$15^{\text {th }}$ International Conference on

AEROSPACE SCIENCES \& AVIATION TECHNOLOGY,

ASAT - 15 - May 28 - 30, 2013, Email: asat@mtc.edu.eg,

Military Technical College, Kobry Elkobbah, Cairo, Egypt,

Tel: +(202) $24025292-24036138$, Fax: +(202) 22621908

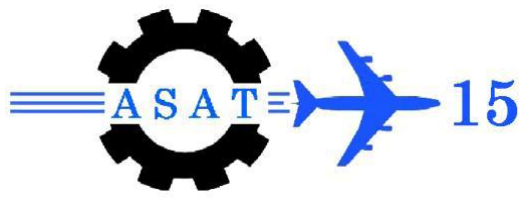

\title{
Novel Cationic Gemini Surfactants with Different Chain Lengths as Corrosion Inhibitors for Carbon Steel in $1 \mathrm{M} \mathrm{HCl}$
}

\author{
\{M. I. Nessim, O. A. A. Elshamy, O. H. Abdelraheem*, and M. M. Osman $\}^{\dagger}$
}

\begin{abstract}
Three cationic gemini surfactants of the type $\mathrm{N}^{2}, \mathrm{~N}^{3}$-dialkyl- $\mathrm{N}^{2}, \mathrm{~N}^{2}, \mathrm{~N}^{3}, \mathrm{~N}^{3}-$ tetramethylbutane diamminium bromide namely $\mathrm{Ia}, \mathrm{Ib}$ and Ic have been synthesized. Their chemical structures were elucidated by the routine methodologies ${ }^{1} \mathrm{H}-\mathrm{NMR}$, elemental analysis and mass spectroscopy. The surface active properties were examined and found to be influenced by the chemical structure of the surfactants. The synthesized cationic gemini surfactants were tested as corrosion inhibitors for pipeline carbon steel API 5LX52 immersed in $1 \mathrm{M} \mathrm{HCl}$ solution, using weight loss method. The obtained data refer to very good inhibitive efficiencies vary with concentrations, and increase in the following order: $\mathrm{Ia}>\mathrm{Ib}>$ Ic. The Quantum chemical parameters such as highest occupied molecular orbital (HOMO), lowest unoccupied molecular orbital (LUMO) energy levels, energy gap ( $\left.\mathrm{E}_{\mathrm{HOMO}}-\mathrm{E}_{\mathrm{LUMO}}\right)$, the dipole moment and charge densities were calculated. The theoretical calculations were in good agreement with corrosion inhibition results.
\end{abstract}

Keywords: Gemini surfactants; Corrosion inhibition; Carbon steel; Weight loss; Surface activities and Quantum chemical parameters.

\section{Introduction}

The application of surfactants as corrosion inhibitors has been studied extensively [1]. Dimeric (gemini) surfactants are a kind of surfactants made up of two identical amphiphilic moieties connected to the level of the head groups by a spacer group, rather than one hydrophilic group and one hydrophobic group for conventional surfactants [2-5]. Indeed, they offer some advantages, such as lower micelle concentration (CMC), higher surface activity and better wetting properties than the corresponding monomeric surfactants [6-11]. Owing to these unique properties, gemini surfactants have been widely used in industrial detergency, gelation of organic solvents, template synthesis of various materials, etc, [12-13]. Therefore, investigation on gemini surfactants is still an attractive subject for research. Considerable efforts have been made to design surfactants, and most of them have been focused on the effect of spacer length or its flexibility and hydophobicity [14-15]. In order to evaluate compounds as corrosion inhibitors and to design novel inhibitors, much more research works were concentrated on the studies of the relationship between structural characteristics of the organic compounds and their inhibiting effects [16].

Quantum chemical methods have already proven to be very useful in determining the molecular structure as well as elucidating the electronic structure and reactivity. Thus, it has become a common practice to carry out quantum chemical calculations in corrosion inhibition

omnia_hassan55@yahoo.com

$\dagger$ Analysis and Evaluation Department, Egyptian Petroleum Research Institute (EPRI).1, Ahmed El- Zomor St., Nasr City 11727 Cairo, Egypt. 
studies. The concept of assessing the efficiency of a corrosion inhibitor with the help of computational chemistry is to search for compounds with desired properties using chemical intuition and experience into a mathematically quantified and computerized form [17-18].

The first goal of this work was to design a series of $\mathrm{N}^{2}, \mathrm{~N}^{3}$-dialkyl- $\mathrm{N}^{2}, \mathrm{~N}^{2}, \mathrm{~N}^{3}, \mathrm{~N}^{3}-$ tetramethylbutane diamminium bromide cationic gemini surfactants, featured with a branched spacer and to investigate their surface activity properties. The second one is to study the inhibitive effect of these surfactants as corrosion inhibitors for carbon steel in $1 \mathrm{M} \mathrm{HCl}$ and discussing the results in the light of the theoretical quantum chemical calculations.

\section{Experimental Methods and Materials}

\subsection{Synthesis}

A series of cationic gemini surfactants of the type $\mathrm{N}^{2}, \mathrm{~N}^{3}$-dialkyl- $\mathrm{N}^{2}, \mathrm{~N}^{2}, \mathrm{~N}^{3}, \mathrm{~N}^{3}-$ tetramethylbutane diaminium bromide namely as Ia, Ib and Ic; (where the alkyl group is dodecyl-, tetradecyl- and hexadecyl- respectively) were synthesized. A mixture of 2,3dibromobutane $(0.05 \mathrm{~mol})$ and $\mathrm{N}, \mathrm{N}$-dimethylalkylamine $(0.0625 \mathrm{~mol})$, is heated in absolute ethanol under reflux for 24 hours, then ethanol is evaporated using the rotary evaporating system. the product was waxy white (due to the presence of the amine in excess). The excess amine was removed by extraction with a mixture of ether-benzene, and finally by an extraction with hexane.

The resulting pure product was recrystallized in pure acetone. The resulting products were confirmed by elemental analysis (Table 1), ${ }^{1} \mathrm{H}-\mathrm{NMR}$ (Table 2) and mass spectroscopy (Table $3 a, b, c)$. The molecular structure of compounds is shown in Fig.1, where n equals $(9,11,13)$ for $\mathrm{Ia}, \mathrm{Ib}$, Ic respectively.

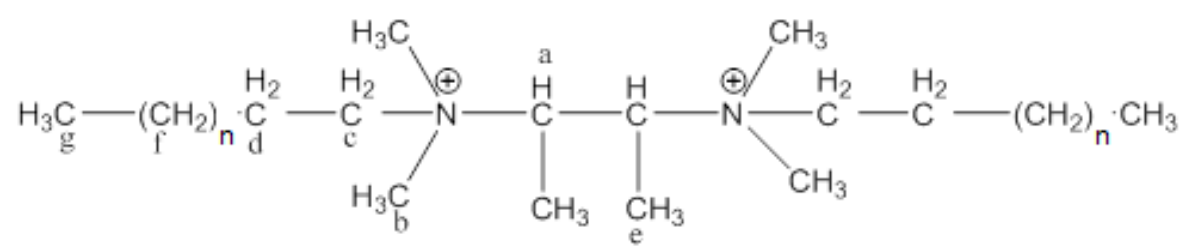

Fig. 1. Molecular structure of synthesized cationic gemini surfactants

Table 1. Elemental analysis of compounds Ia, Ib and Ic

\begin{tabular}{c|c|c|c|c|c|c|c|c}
\hline \hline Element \% & \multicolumn{2}{|c|}{$\mathrm{C} \%$} & \multicolumn{2}{c|}{$\mathrm{H} \%$} & \multicolumn{2}{c|}{ Br\% } & \multicolumn{2}{c}{$\mathrm{N} \%$} \\
\hline Surfactant & Calc. & Obs. & Calc. & Obs. & Calc. & Obs. & Calc. & Obs. \\
\hline Ia & 59.81 & 59.58 & 10.90 & 10.72 & 24.92 & 24.95 & 4.36 & 4.75 \\
\hline Ib & 61.87 & 61.85 & 11.25 & 11.40 & 22.89 & 22.67 & 4.01 & 4.08 \\
\hline Ic & 63.64 & 63.45 & 11.48 & 11.52 & 21.17 & 21.36 & 3.71 & 3.65 \\
\hline \hline
\end{tabular}

\subsection{Measurement of Surface Tension}

The surface tension, at air/liquid interface, of the three synthesized cationic gemini surfactants was determined at $35^{\circ} \mathrm{C}$, measured using De-Nouy Tensiometer (Kruss K6 type) which calibrated against distilled water (specific conductivity $1.1 \times 10^{-6} \mathrm{ohm}^{-1} \mathrm{~cm}^{-1}$ at $30^{\circ} \mathrm{C}$ ) [19]. Freshly prepared aqueous solution of the surfactants (Ia, Ib and Ic), in deionized water was prepared with a concentration range $0.01-10 \mathrm{mmol} / \mathrm{L}$. 
Table 2. ${ }^{1} \mathrm{H}-\mathrm{NMR}$ spectroscopy of Ia, Ib and Ic

\begin{tabular}{c|c|c}
\hline \hline Type of proton & Chemical Shift $(\delta) \mathrm{ppm}$ & Spin multiplicity \\
\hline $\mathrm{a}$ & 3.88 & Quartet \\
\hline $\mathrm{b}$ & 3.44 & Singlet \\
\hline $\mathrm{c}$ & 3.32 & Triplet \\
\hline $\mathrm{d}$ & 2.09 & Multiplet \\
\hline $\mathrm{e}$ & 1.66 & Doublet \\
\hline $\mathrm{f}$ & 1.22 & Multiplet \\
\hline $\mathrm{g}$ & 0.86 & Triplet \\
\hline \hline
\end{tabular}

Table 3a Mass spectroscopy of $\mathrm{m} / \mathrm{z} 642\left(\mathrm{C}_{32} \mathrm{H}_{70} \mathrm{Br}_{2} \mathrm{~N}_{2}\right)$

\begin{tabular}{c|c|c|c}
\hline \hline $\mathrm{m} / \mathrm{z}$ & Molecular Formula & $\mathrm{m} / \mathrm{z}$ & Molecular formula \\
\hline 642 & $\left.\mathrm{C}_{32} \mathrm{H}_{70} \mathrm{Br}_{2} \mathrm{~N}_{2}\right]^{3+}$. & 253 & $\left.\mathrm{C}_{16} \mathrm{H}_{33} \mathrm{~N}_{2}\right]^{3+}$ \\
\hline 482 & $\left.\mathrm{C}_{32} \mathrm{H}_{70} \mathrm{~N}_{2}\right]^{3+}$ & 211 & $\left.\mathrm{C}_{14} \mathrm{H}_{29} \mathrm{~N}\right]^{2+}$ \\
\hline 467 & $\left.\mathrm{C}_{31} \mathrm{H}_{67} \mathrm{~N}_{2}\right]^{3+}$ & 98 & $\left.\mathrm{C}_{6} \mathrm{H}_{12} \mathrm{~N}\right]^{2+}$ \\
\hline 452 & $\left.\mathrm{C}_{30} \mathrm{H}_{64} \mathrm{~N}_{2}\right]^{3+}$ & 43 & $\left.\mathrm{C}_{2} \mathrm{H}_{5} \mathrm{~N}\right]^{2+.}$ \\
\hline 283 & $\left.\mathrm{C}_{18} \mathrm{H}_{39} \mathrm{~N}_{2}\right]^{3+}$ & 29 & $\left.\mathrm{CH}_{2} \mathrm{~N}\right]^{2+.}$ \\
\hline 268 & $\left.\mathrm{C}_{17} \mathrm{H}_{36} \mathrm{~N}_{2}\right]^{3+.}$ & & \\
\hline \hline
\end{tabular}

Table 3b Mass spectroscopy of Ib $\mathrm{m} / \mathrm{z} 698\left(\mathrm{C}_{36} \mathrm{H}_{78} \mathrm{Br}_{2} \mathrm{~N}_{2}\right)$

\begin{tabular}{c|c|c|c}
\hline \hline $\mathrm{m} / \mathrm{z}$ & Molecular Formula & $\mathrm{m} / \mathrm{z}$ & Molecular formula \\
\hline 698 & $\left.\mathrm{C}_{36} \mathrm{H}_{+} \mathrm{Br}_{2} \mathrm{~N}_{2}\right]^{3+.}$ & 283 & $\left.\mathrm{C}_{18} \mathrm{H}_{37} \mathrm{~N}_{2}\right]^{3+.}$ \\
\hline 538 & $\left.\mathrm{C}_{36} \mathrm{H}_{78} \mathrm{~N}_{2}\right]^{3+.}$ & 241 & $\left.\mathrm{C}_{16} \mathrm{H}_{25} \mathrm{~N}\right]^{2+.}$ \\
\hline 525 & $\left.\mathrm{C}_{35} \mathrm{H}_{75} \mathrm{~N}_{2}\right]^{3+.}$ & 98 & $\left.\mathrm{C}_{6} \mathrm{H}_{12} \mathrm{~N}\right]^{2+.}$ \\
\hline 510 & $\left.\mathrm{C}_{34} \mathrm{H}_{72} \mathrm{~N}_{2}\right]^{3+.}$ & 43 & $\left.\mathrm{C}_{2} \mathrm{H}_{5} \mathrm{~N}\right]^{2+.}$ \\
\hline 313 & $\left.\mathrm{C}_{20} \mathrm{H}_{43} \mathrm{~N}_{2}\right]^{3+.}$ & 29 & $\left.\mathrm{CH}_{2} \mathrm{~N}\right]^{2+.}$ \\
\hline 298 & $\left.\mathrm{C}_{19} \mathrm{H}_{40} \mathrm{~N}_{2}\right]^{3+.}$ & & \\
\hline \hline
\end{tabular}

Table 3c Mass spectroscopy of Ic $\mathrm{m} / \mathrm{z} 754\left(\mathrm{C}_{40} \mathrm{H}_{86} \mathrm{Br}_{2} \mathrm{~N}_{2}\right)$

\begin{tabular}{c|c|c|c}
\hline \hline $\mathrm{m} / \mathrm{z}$ & Molecular Formula & $\mathrm{m} / \mathrm{z}$ & Molecular formula \\
\hline 754 & $\left.\mathrm{C}_{40} \mathrm{H}_{86} \mathrm{Br}_{2} \mathrm{~N}_{2}\right]^{3+.}$ & 309 & $\left.\mathrm{C}_{20} \mathrm{H}_{41} \mathrm{~N}_{2}\right]^{3+.}$ \\
\hline 594 & $\left.\mathrm{C}_{40} \mathrm{H}_{86} \mathrm{~N}_{2}\right]^{3+.}$ & 267 & $\left.\mathrm{C}_{18} \mathrm{H}_{37} \mathrm{~N}\right]^{2+.}$ \\
\hline 579 & $\left.\mathrm{C}_{39} \mathrm{H}_{83} \mathrm{~N}_{2}\right]^{3+.}$ & 98 & $\left.\mathrm{C}_{6} \mathrm{H}_{12} \mathrm{~N}\right]^{2+.}$ \\
\hline 564 & $\left.\mathrm{C}_{38} \mathrm{H}_{80} \mathrm{~N}_{2}\right]^{3+.}$ & 43 & $\left.\mathrm{C}_{2} \mathrm{H}_{5} \mathrm{~N}\right]^{2+}$ \\
\hline 339 & $\left.\mathrm{C}_{22} \mathrm{H}_{47} \mathrm{~N}_{2}\right]^{3+.}$ & 29 & $\left.\mathrm{CH}_{2} \mathrm{~N}\right]^{2+.}$ \\
\hline 324 & $\left.\mathrm{C}_{21} \mathrm{H}_{44} \mathrm{~N}_{2}\right]^{3+.}$ & & \\
\hline \hline
\end{tabular}




\subsection{Weight Loss Measurements}

Specimens of low carbon steel with dimensions $(1 \mathrm{~cm} \times 1 \mathrm{~cm} \times 0.5 \mathrm{~cm})$ were used. Carbon steel grade is (API 5L X52) with chemical composition C: $0.28 \%$, Si: 0.24\%, Mn: 1.24\%, P: $0.013 \%, \mathrm{Cr}: 0.02 \%, \mathrm{Ni}: 0.02 \%, \mathrm{Al}: 0.03 \%$ and the rest is Fe. Prior to immersion, the specimens were abraded in sequence using emery papers of grade number 220, 320, 400, 600, 800,1000 and 1200. The samples were allowed to stand for $72 \mathrm{hr}$ in $1 \mathrm{M} \mathrm{HCl}$ solution in the absence and presence of different concentrations of inhibitors ranged from $4 \times 10^{-5}$ to $4 \times 10^{-3}$ mol. $1^{-1}$. All tests are run in duplicate and the calculated weight losses are averaged.

\subsection{Quantum Chemical Calculations}

Quantum mechanical program Chem Bio Draw Ultra 12, was used for molecular modeling. The calculations were based on $\mathrm{Ab}$ initio (HF/3-21G and MP2/3-21G) and semiemperical (MNDO, AM1 and PM3) methods.

\section{Results and Discussion}

\subsection{Surface Properties}

The critical micelle concentrations CMC of the investigated surfactants were determined at $35^{\circ} \mathrm{C}$ by plotting the surface tension in $\mathrm{mN} \mathrm{m}^{-1}$, versus log concentration as shown in Fig. 2 . The abrupt change in the linear line was taken as a critical micelle concentration. The CMC values together with other surface parameters are listed in Table 4. By careful inspection $\mathrm{CMC}$ decreases as the hydrophobicity increases.

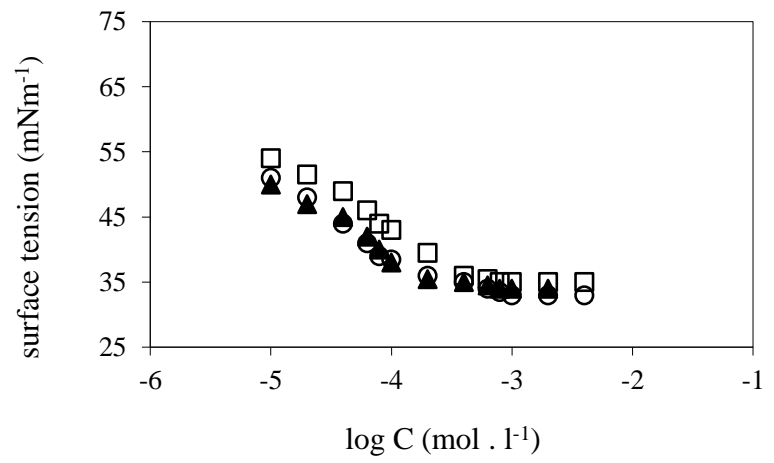

( $\Delta)$ Ia; (o) Ib; and ( $\square)$ Ic.

Fig. 2. Variation of surface tension with $\log \mathrm{C}$

Table 4. Surface properties of the synthesized gemini surfactants

\begin{tabular}{c|c|c|c|c}
\hline Surfactants & $\mathrm{CMC} \times 10^{4}$ & $\Gamma_{\max } \times 10^{10}$ & Amin & $\Pi$ \\
\hline $\mathrm{Ia}$ & 4.89 & 1.83 & 0.91 & 34.50 \\
\hline $\mathrm{Ib}$ & 4.47 & 3.75 & 0.44 & 30.50 \\
\hline $\mathrm{Ic}$ & 3.16 & 4.24 & 0.39 & 28.50 \\
\hline \hline
\end{tabular}

The surface excess concentration $\Gamma_{\max }\left(\mathrm{mol} / \mathrm{cm}^{2}\right)$ by applying Gibbs equation [20].

$$
\Gamma_{\max }=-\frac{1}{2.303 n R T} \frac{d \gamma}{\operatorname{dlog} C}
$$

where $\mathrm{R}$ is the gas constant $(8.314 \mathrm{~J} / \mathrm{mol})$ and $\mathrm{T}$ is the absolute temperature. The constant $\mathrm{n}$ takes value equals 2 for an ionic surfactants, were the surfactant ion and the counter ion are 
univalent, and $\mathrm{n}=3$ for a dimeric surfactant made up of divalent surfactant ion and two univalent counter ions, in absence of swamping electrolyte [21].

The $\Gamma_{\max }$ values in Table 4 were used to calculate the minimum area per molecule, $A_{\min }$ in $\AA^{2} /$ molecule at the aqueous phase interface using the relationship:

$$
\mathrm{A}_{\min }=\frac{10^{16}}{N_{A} \Gamma_{\max }}
$$

where, $\mathrm{N}_{\mathrm{A}}$ : Avogadro's number, $6.023 \times 10_{23}$. There was slight increase in $\Gamma_{\max }$ and decrease in $A_{\text {min }}$ by increase in the hydrophobic chain length which might be caused from increasing van der Vaals interaction. The effectiveness $\left(\pi_{\mathrm{cmc}}\right)$, which indicate the surface activity of the surfactants molecules at their CMCs were determined. The effectiveness in surface tension reduction $\left(\pi_{\mathrm{cmc}}\right)$ of the prepared surfactants at $35^{\circ} \mathrm{C}$ revealed that Ia has the higher value.

\subsection{Weight Loss Measurements}

The inhibition efficiency E\%. was determined by the following equation [22]:

$$
\begin{gathered}
\theta=1-(\Delta \mathrm{Wi} / \Delta \mathrm{Wo}) \\
\mathrm{E} \%=1-(\Delta \mathrm{Wi} / \Delta \mathrm{Wo}) \times 100
\end{gathered}
$$

where $\mathrm{E} \%$ is the corrosion inhibition efficiency, $\theta$ is coverage of the metal surface and $\Delta \mathrm{W}_{\mathrm{o}}$ and $\Delta \mathrm{W}_{\mathrm{i}}$ are the weight loss per unit area in absence and presence of inhibitors respectively. The results listed in Table 5. The plotting of surface coverage $(\theta)$ against $\log C$ illustrated in Fig 4. The corrosion rate is a concentration dependent, where efficiency (E\%) increases with increasing inhibitors concentration and reaches the maximum value near CMC. The inhibition efficiency found to be ranked as follows, Ia> Ib > Ic. It means that the efficiency decreases by increasing the tail chain length of the synthesized gemini surfactants with branched spacer.

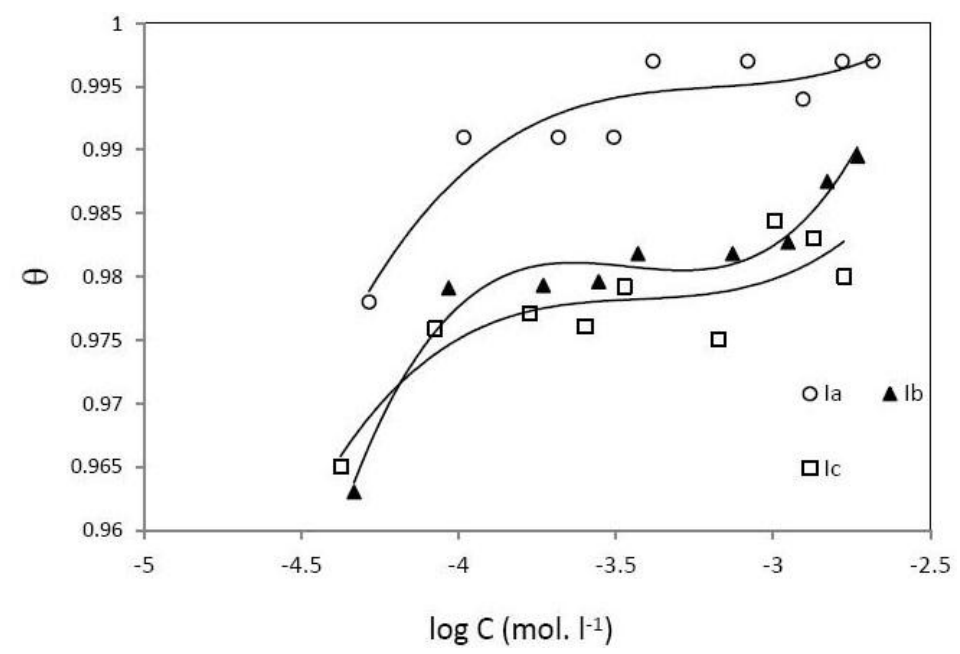

Fig. 3 Variation of the inhibition efficiency of carbon steel in the presence of different concentrations of the inhibitors

The inhibitors having $\theta$ near unity, is indicating almost a full coverage of the metal surface with adsorbed surfactant molecules as a good physical barrier shielding the corroding surface from the corrosive medium. From surface activity measurements (Table 4), the greatest effectiveness in surface tension reduction $\left(\pi_{\mathrm{cmc}}\right)$ was achieved by Ia compared with that obtained by the other two surfactants, which may explain the highest inhibition efficiency achieved by Ia. 
Table 5 The corrosion inhibition and surface coverage of carbon steel in $1 \mathrm{M}$ HCl with addition of surfactants Ia, Ib and Ic

\begin{tabular}{|c|c|c|c|}
\hline Surfactants & Conc. $\left(\mathrm{mol}^{-1} \mathrm{l}^{-1}\right)$ & $\theta$ & $\mathrm{E} \%$ \\
\hline \multirow{9}{*}{ Ia } & $4 \times 10^{-5}$ & 0.9780 & 97.80 \\
\hline & $1 \times 10^{-4}$ & 0.9910 & 99.10 \\
\hline & $2 \times 10^{-4}$ & 0.9910 & 99.10 \\
\hline & $3 \times 10^{-4}$ & 0.9910 & 99.10 \\
\hline & $4 \times 10^{-4}$ & 0.9970 & 99.70 \\
\hline & $8 \times 10^{-4}$ & 0.9970 & 99.70 \\
\hline & $1 \times 10^{-3}$ & 0.9940 & 99.40 \\
\hline & $2 \times 10^{-3}$ & 0.9970 & 99.70 \\
\hline & $4 \times 10^{-3}$ & 0.9970 & 99.70 \\
\hline \multirow{9}{*}{$\mathrm{Ib}$} & $4 \times 10^{-5}$ & 0.9630 & 96.30 \\
\hline & $1 \times 10^{-4}$ & 0.9791 & 97.91 \\
\hline & $2 \times 10^{-4}$ & 0.9793 & 97.93 \\
\hline & $3 \times 10^{-4}$ & 0.9796 & 97.96 \\
\hline & $4 \times 10^{-4}$ & 0.9818 & 98.18 \\
\hline & $8 \times 10^{-4}$ & 0.9818 & 98.18 \\
\hline & $1 \times 10^{-3}$ & 0.9827 & 98.27 \\
\hline & $2 \times 10^{-3}$ & 0.9875 & 98.75 \\
\hline & $4 \times 10^{-3}$ & 0.9895 & 98.95 \\
\hline \multirow{9}{*}{ Ic } & $4 \times 10^{-5}$ & 0.9650 & 96.50 \\
\hline & $1 \times 10^{-4}$ & 0.9759 & 97.59 \\
\hline & $2 \times 10^{-4}$ & 0.9771 & 97.71 \\
\hline & $3 \times 10^{-4}$ & 0.9760 & 97.60 \\
\hline & $4 \times 10^{-4}$ & 0.9792 & 97.92 \\
\hline & $8 \times 10^{-4}$ & 0.9750 & 97.50 \\
\hline & $1 \times 10^{-3}$ & 0.9844 & 98.44 \\
\hline & $2 \times 10^{-3}$ & 0.9830 & 98.30 \\
\hline & $4 \times 10^{-3}$ & 0.9800 & 98.00 \\
\hline
\end{tabular}

\subsection{Adsorption Isotherm}

The inhibition efficiency has been found to be closely related to inhibitor adsorption abilities and molecular properties for different kinds of organic compounds [23]. In order to determine the adsorption mode, various isotherms were tested and by far the best fit was obtained with the Langmuir isotherm Fig. 4. by the following relation [24]:

$$
\frac{\mathrm{C}}{\theta}=\frac{1}{\mathrm{Kads}}+\mathrm{C}
$$

where $C$ is the concentration of the inhibitor, $\Theta$ is the surface coverage and $K_{a d s}$ is the equilibrium adsorption constant Table 6. shows the parameters and the regression factor calculated from Langmuir adsorption isotherm. All correlation coefficients $\left(\mathrm{r}^{2}\right)$ exceeded 0.99 indicates that the corrosion inhibition of carbon steel by the prepared cationic gemini 
surfactants was attributed to adsorption of these compounds on the metal surface. However, the slopes of the $\mathrm{C} / \theta$ versus $\mathrm{C}$ plots show a little deviation from unity, This deviation may be explained on the basis of interaction between the adsorbed species on the metal surface by mutual repulsion or attraction [25].

High values of the adsorption constant $\mathrm{K}_{\mathrm{ads}}$ can be reasoned for better adsorption and high inhibition efficiency [26], which is consistent with data obtained from weight loss investigations.

Table 6. Adsorption parameters of inhibitors surfactants on the steel surface.

\begin{tabular}{c|c|c|c}
\hline \hline Surfactant & $\begin{array}{c}\text { Linear correlation } \\
\text { coefficient, } \mathrm{r}^{2}\end{array}$ & Slope & $\begin{array}{c}\text { Kads } \\
\left(1 . \mathrm{mol}^{-1}\right)\end{array}$ \\
\hline $\mathrm{Ia}$ & 0.9999 & 1.0028 & $98.3768 \times 10^{4}$ \\
\hline $\mathrm{Ib}$ & 0.9999 & 1.0110 & $97.6685 \times 10^{4}$ \\
\hline $\mathrm{Ic}$ & 0.9999 & 1.0183 & $90.0556 \times 10^{4}$ \\
\hline
\end{tabular}

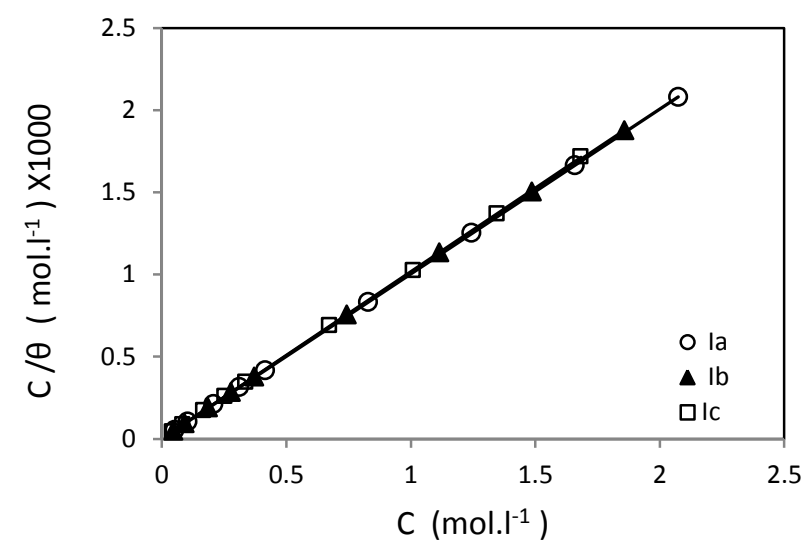

Fig. 4. Langmuir isotherm plots for carbon steel in $1 \mathrm{M} \mathrm{HCl}$ at presence of different concentrations of cationic gemini surfactants Ia, Ib and Ic.

\subsection{Quantum Chemical Calculations}

Using the $\mathrm{Ab}$ initio (HF/3-21G and MP2/3-21G) and semiempirical (AM1, MNDO and PM3) methods of calculations by Chem Bio Draw Ultra 12 software, the Huckel and Mulliken charges, the dipole moments, $\mathrm{E}_{\mathrm{HOMO}}$ (the highest occupied molecular orbital) and $\mathrm{E}_{\mathrm{LUMO}}$ (the lowest unoccupied molecular orbital) values were calculated. The charges representative atoms and other relevant quantum parameters were listed in Tables 7,8 and 9. The optimized structure of the molecules and the electric/orbital density distributions of HOMO and LUMO are illustrated in Fig.5 and Fig.6 respectively.

Mulliken population analysis is mostly used for the calculation of the charge distribution in a molecule [27]. These numerical quantities are easy to obtain and they provide at least a qualitative understanding of the structure and reactivity of molecules [28]. Furthermore, atomic charges are used for the description of the molecular polarity of molecules. By careful examination of Tables 7,8 and 9 , it is found that the values of the electronegative charges of the N13, N15, N16, N17, N18, and N20, were irrelevant to the inhibition efficiency. These 
results suggested that the adsorptions might not be attributed to a chemical bond between the electronegative atoms and the metal surface.

The dipole moment $(\mu)$ values were founded to be increased by the increase in the hydrophobic chain length. It may indicated that the adsorptions might not be arisen from intermolecular electrostatic force [16]. Highest occupied molecular orbital energy $\left(\mathrm{E}_{\mathrm{HOMO}}\right)$ and lowest unoccupied molecular orbital energy $\left(\mathrm{E}_{\text {LUMO }}\right)$ are very popular quantum chemical parameters. These orbitals, also called the frontier orbitals, determine the way the molecule interacts with other species. The HOMO is the orbital that could act as an electron donor, since it is the outermost (highest energy) orbital containing electrons. The LUMO is the orbital that could act as the electron acceptor, since it is the innermost (lowest energy) orbital that has room to accept electrons. According to the frontier molecular orbital theory, the formation of a transition state is due to an interaction between the frontier orbitals (HOMO and LUMO) of reactants [29].

Table 7 Quantum Chemical Parameters of Ia

\begin{tabular}{llllll}
\hline \hline Quantum parameters & $\mathrm{HF}(3-21 \mathrm{G})$ & $\mathrm{MP} 2(3-21 \mathrm{G})$ & $\mathrm{AM} 1$ & MNDO & PM3 \\
\hline $\mathrm{E}_{\text {HOMO }}(\mathrm{eV})$ & 23.790 & 23.778 & 23.776 & 23.783 & 23.781 \\
$\mathrm{E}_{\text {LUMO }}(\mathrm{eV})$ & 25.736 & 25.741 & 25.740 & 25.741 & 25.739 \\
$\mathrm{E}_{\text {LUMO-HOMO }}(\mathrm{eV})$ & 01.946 & 01.963 & 01.964 & 01.958 & 01.958 \\
& $\mathrm{~N}_{13}=0.4906$ & $\mathrm{~N}_{13}=0.4915$ & $\mathrm{~N}_{13}=0.4907$ & $\mathrm{~N}_{13}=0.4908$ & $\mathrm{~N}_{13}=0.4910$ \\
Huckel charge $(\mathrm{eV})$ & $\mathrm{N}_{16}=0.4867$ & $\mathrm{~N}_{16}=0.4871$ & $\mathrm{~N}_{16}=0.4864$ & $\mathrm{~N}_{16}=0.4868$ & $\mathrm{~N}_{16}=0.4873$ \\
& $\mathrm{~N}_{13}=-0.7385$ & $\mathrm{~N}_{13}=-0.7423$ & $\mathrm{~N}_{13}=0.0191$ & $\mathrm{~N}_{13}=-0.1068$ & $\mathrm{~N}_{13}=0.5958$ \\
Mulliken charge $(\mathrm{eV})$ & $\mathrm{N}_{16}=-0.7390$ & $\mathrm{~N}_{16}=-0.7395$ & $\mathrm{~N}_{16}=0.0301$ & $\mathrm{~N}_{16}=-0.0979$ & $\mathrm{~N}_{16}=0.6185$ \\
$\mu$ (Debye) & 29.67 & 29.47 & 29.97 & 31.03 & 30.33 \\
\hline \hline
\end{tabular}

Table 8 Quantum chemical parameters of Ib

\begin{tabular}{llllll}
\hline \hline Quantum parameters & $\mathrm{HF}(3-21 \mathrm{G})$ & $\mathrm{MP} 2 / 3-21 \mathrm{G}$ & $\mathrm{AM} 1$ & MNDO & PM3 \\
\hline $\mathrm{E}_{\text {HOMO }}(\mathrm{eV})$ & 23.778 & 23.778 & 23.779 & 23.780 & 23.784 \\
$\mathrm{E}_{\text {LUMO }}(\mathrm{eV})$ & 25.737 & 25.739 & 25.747 & 25.746 & 25.745 \\
$\mathrm{E}_{\text {LUMO-HOMO }}(\mathrm{eV})$ & 1.959 & 01.961 & 1.968 & 1.966 & 1.961 \\
Huckel charge $(\mathrm{ev})$ & $\mathrm{N}_{15}=0.4913$ & $\mathrm{~N}_{15}=0.4912$ & $\mathrm{~N}_{15}=0.5542$ & $\mathrm{~N}_{15}=0.4912$ & $\mathrm{~N}_{15}=0.4574$ \\
& $\mathrm{~N}_{18}=0.4877$ & $\mathrm{~N}_{18}=0.4872$ & $\mathrm{~N}_{18}=0.6502$ & $\mathrm{~N}_{18}=0.4876$ & $\mathrm{~N}_{18}=0.4926$ \\
Mulliken charge $(\mathrm{ev})$ & $\mathrm{N}_{15}=-0.7398$ & $\mathrm{~N}_{15}=-0.7424$ & $\mathrm{~N}_{15}=0.0179$ & $\mathrm{~N}_{15}=-0.1068$ & $\mathrm{~N}_{15}=0.5587$ \\
$\mu$ (Debye) & $\mathrm{N}_{18}=-0.7403$ & $\mathrm{~N}_{13}=-0.7379$ & $\mathrm{~N}_{18}=0.0304$ & $\mathrm{~N}_{18}=-0.0983$ & $\mathrm{~N}_{18}=0.5857$ \\
\hline \hline
\end{tabular}

Table 9 Quantum chemical parameters of Ic

\begin{tabular}{llllll}
\hline \hline Quantum parameters & $\mathrm{HF}(3-21 \mathrm{G})$ & $\mathrm{MP} 2 / 3-21 \mathrm{G}$ & $\mathrm{AM}$ & MNDO & PM3 \\
\hline $\mathrm{E}_{\text {HOMO }}(\mathrm{eV})$ & 23.774 & 23.774 & 23.760 & 23.767 & 23.778 \\
$\mathrm{E}_{\text {LUMO }}(\mathrm{eV})$ & 25.739 & 25.743 & 25.734 & 25.741 & 25.746 \\
$\mathrm{E}_{\text {LUMO-HOMO }}(\mathrm{eV})$ & 1.965 & 1.969 & 1.974 & 1.974 & 1.968 \\
Huckel charge $(\mathrm{eV})$ & $\mathrm{N}_{17}=0.4906$ & $\mathrm{~N}_{17}=0.4857$ & $\mathrm{~N}_{17}=0.4904$ & $\mathrm{~N}_{17}=0.4904$ & $\mathrm{~N}_{17}=0.4526$ \\
& $\mathrm{~N}_{20}=0.4874$ & $\mathrm{~N}_{20}=0.4746$ & $\mathrm{~N}_{20}=0.4874$ & $\mathrm{~N}_{20}=0.4871$ & $\mathrm{~N}_{20}=0.4921$ \\
Mulliken charge $(\mathrm{eV})$ & $\mathrm{N}_{17}=-0.7396$ & $\mathrm{~N}_{17}=-0.7411$ & $\mathrm{~N}_{17}=-0.0191$ & $\mathrm{~N}_{17}=-0.1068$ & $\mathrm{~N}_{17}=0.5581$ \\
$\mu$ (Debye) & $\mathrm{N}_{20}=-0.7103$ & $\mathrm{~N}_{20}=-0.7378$ & $\mathrm{~N}_{20}=-0.0302$ & $\mathrm{~N}_{20}=-0.0978$ & $\mathrm{~N}_{20}=0.5843$ \\
\hline \hline
\end{tabular}




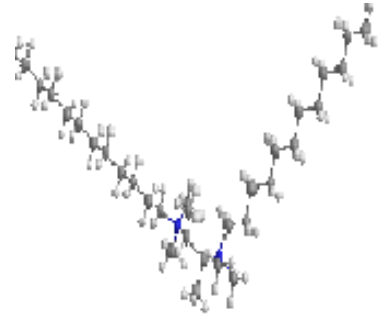

(a)

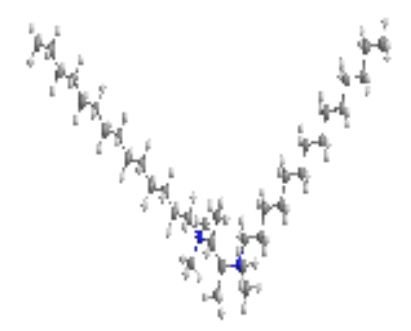

(b)

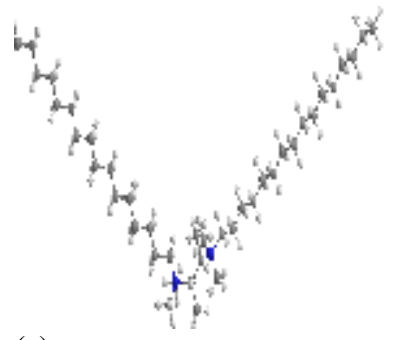

(c)

Fig. 5. Optimized structure of the synthesized cationic gemini surfactants of the type $\mathbf{N}^{2}, \mathbf{N}^{3}$-dialkyl- $\mathbf{N}^{2}, \mathbf{N}^{2}, \mathbf{N}^{3}, \mathbf{N}^{3}$-tetramethylbutane diamminium bromide:

(a) Ia; (b) Ib; (c) Ic

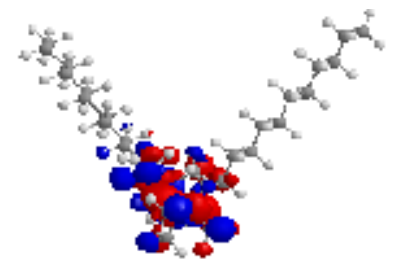

HOMO

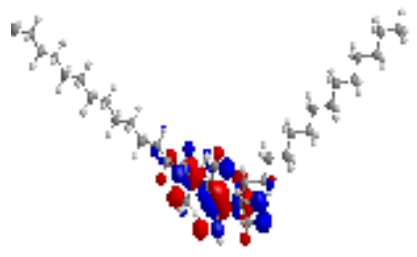

HOMO

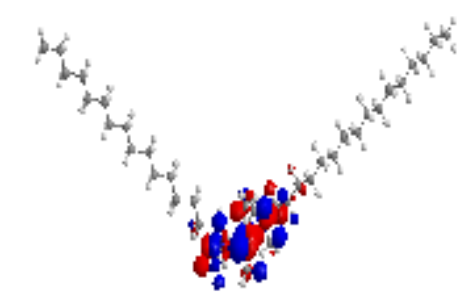

HOMO

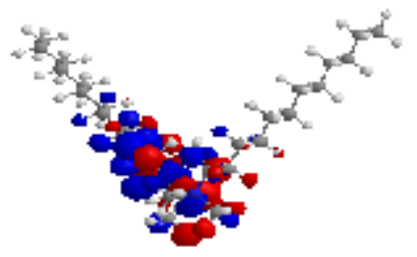

LUMO

(a)

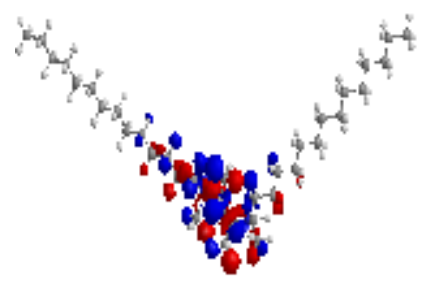

LUMO

(b)

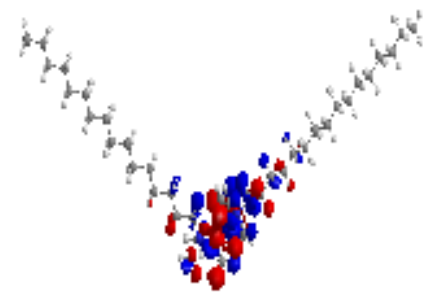

LUMO

(c)

Fig. 6. The frontier molecule orbital density distributions of the prepared three cationic gemini surfactants of the type $\mathrm{N}^{2}, \mathrm{~N}^{3}$-dialkyl- $\mathrm{N}^{2}, \mathrm{~N}^{2}, \mathrm{~N}^{3}, \mathrm{~N}^{3}$-tetramethylbutane diamminium bromide: (a) Ia; (b) Ib; (c) Ic.

From Tables 6, 7 and 8 it is found that the $E_{H O M O}$ and the $E_{L U M O}$ changed rulelessly, while the energy gap $E_{L U M O^{-}} E_{H O M O}$; the difference in energy between the $E_{\text {HOMO }}$ and $E_{L U M O}$ decreased with increasing the inhibition efficiency. The energy gap $(\Delta E)$ is an important stability index [30]. A large HOMO-LUMO gap implies high stability for the molecule in chemical reactions [31]. 
The values of $(\Delta E)$ indicates remarkably that the smaller energy gap results in a high corrosion inhibition, reflecting the stronger interaction between the inhibitors and metal surface. The interactions are probably physical adsorption [32-34].

An attempt to search correlations among the experimentally obtained inhibition efficiency results and theoretically calculated quantum parameter; energy gap $(\Delta E)$ values; are illustrated in Fig.7. The plotting shows that the best correlation obtained using semi empirical methods MNDO and AM1. This result is in accordance with other works [18, 23, 35 and 36].
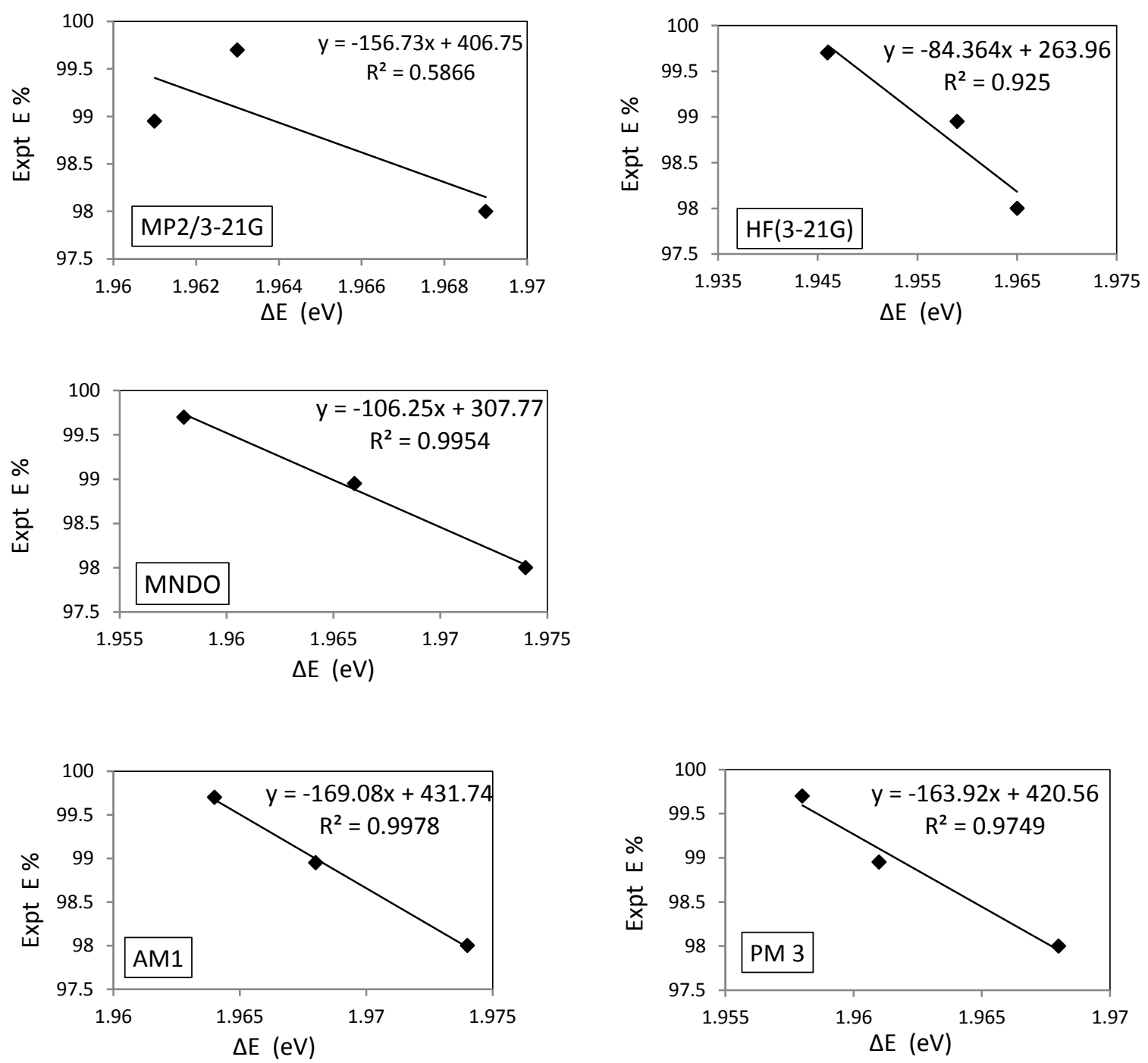

\section{Fig. 7 Correlations between experimental $\% \mathrm{E}$ and calculated quantum chemical parameter $(\Delta \mathrm{E})$.}

\section{Conclusions}

Novel synthesized cationic gemini surfactants featured with a branched spacer ,showed good inhibition properties for the corrosion of pipeline carbon steel API X52 in $1 \mathrm{M} \mathrm{HCl}$ solutions, and the inhibition efficiency increased as their concentration increases.

Based on the weight loss measurements, the inhibiting efficiencies of cationic gemini surfactants followed the order of Ia $>\mathrm{Ib}>\mathrm{Ic}$, which is the same order of effectivness in surface tension reduction.

The adsorption of studied cationic gemini surfactants on the carbon steel obeyed the Langmuir adsorption isotherm model. 
The experimentally obtained inhibition efficiency was correlated with energy gap which is theoretically calculated by quantum chemical calculations. The correlation was wellproportioned suggested the adsorption of synthesized cationic gemini surfactants on the carbon steel was physical adsorption.

\section{References}

[1] L. Qiu A. Xie, Y. Shen, Applied Surface Science ,246,1 (2005).

[2] L.Grosmaire, M. Chorro, C. Chorro, S. Partyka, R. Zana, , Colloid Polym. Sci. ,115,31 (2000).

[3] R. Zana, , Adv. Colloid interface Sci., 97, 205 (2002).

[4] M. Pisarcik, M.J. Rosen, M. Polakovicova, F. Devinsky, I. Lacko, , J. Colloid interface Sci., 289, 560 (2005).

[5] Y.X. Wang, Y.C. Han, X. Huang, M.W. Cao, Y.L. Wang, , J. Colloid interface Sci., 319, 534 (2008).

[6] Zana, M. Benrraou, R. Rueff, Lngmuir, 7, 1072 (1991).

[7] C. Chorro, M. Chorro, O. Dolladille, S. Partyka, R. Zana, J. Colloid interface Sci., 199, 169 (1998).

[8] R. Oda, I. Huc, S.J. Canadau, Chem. Commun., 2105, (1997).

[9] F.L. Duivenvoorde, M.C. Feiters, S.J. van der Gaast, J.B.F.N. Engberts, Langmuir ,13, 3737 (1997).

[10] R. Zana, J.D. Xia, in: R. Zana, J.D. Xia (Eds.), Gemini Surfactants, Dekker, New York, (2004).

[11] T. Lu, F. Han, G.R. Mao, G.F. Lin, J.B. Huang, X. Huang, Y.L. Wang, H.L. Fu, Langmuir, 23, 2932 (2007).

[12] S.H. Han, J. Xu, W.G. Hou, X.M. Yu, Y.S. Wang, J. Phys. Chem. B ,108, 15043 (2004).

[13] T. Lu, Y. Lan, Ch. Liu, J. Huang, Y. Wan, J. Colloid Interface Si., 377, 222 (2012).

[14] L. Grosmaire, M. Chorro, C. Chorro, S. Partyka, R. Zana, , Prog Colloid Polym. Sci,. 115, 31 (2000).

[15] L. Grosmaire, M. Chorro, C. Chorro, S. Partyka, S. Lagerge,, Thermocheimica Acta, 379, 255 (2001).

[16] Y. Yan, W. Li , L. Cai, B. Hou, Electrochimica Acta, 53, 5953 (2008).

[17] E. Kraka, D. Cremer, J. Am. Chem. Soc., 122, 8245 (2000).

[18] G. Gece, Corrosion Science, 50, 2981 (2008).

[19] M.J. Rosen, M.L. Baum and F. Kasher, JAOCS, 53, 742 (1976).

[20] M.J. Rosen, Surfactants and Interfacial phenomena. John Wiley \& Sons, New York (1978).

[21] E. Alami, S. Abrahmsen-Alami, J. Eastoe, R.K. Heenan, , Langmuir, 19 (2003) 1821.

[22] A.M.Badawi, M.A.Hegazy, A.A.El-Sawy, H.M.Ahmed ,W.W.Kamel, Marerials Chemistry and Physics, 124,458 (2010).

[23] T. Arslan, F. Kandemirli , E.E. Ebenso, I. Love, H. Alemu, Corrosion Science, 51, 35 (2009).

[24] A.S. Fouda, A.A. Al-Sarawy, F.Sh. Ahmed, H.M. El-Abbasy Corrosion Science, Volume 51, Issue 3, 485 (2009).

[25] A.A Abdel-Azim., L.A Shalaby., H Abbas., Corros. Sci., 14, 21 (1974).

[26] M.A. Hegazy, Corrosion Science, 51,2610 (2009).

[27] J.N. Murrell, S.F. Kettle, J.M. Tedder, The Chemical Bond, John Wiley \& Sons, Chichester, 1985.

[28] C. Gruber, V. Buss, Chemosphere, 19,1595 (1989). 
[29] K. Fukui, Theory of Orientation and Stereoselection, Springer-Verlag, New York, (1975).

[30] D.F.V. Lewis, C. Ioannides, D.V. Parke, , Xenobiotica, 24,401 (1994).

[31] Z. Zhou, R.G. Parr, J. Am. Chem. Soc. ,112, 5720 (1990) .

[32] I. Lukovits, K. Palfi, E. Kalman, Corrosion 53, 915 (1997).

[33] M. O“ zcan, 'I. Dehri, Prog. Org. Coat. 51, 181 (2004).

[34] Y. Yana,,W. Li , L. Caia, B. Hou, Electrochimica Acta, 53, 5953 (2008).

[35] G.Bereket, E.Hür, C.Öğretir journal of molecular Structure (Theochem) 578, 79 (2002).

[36] I. Ahamad, R. Prasad, M.A. Quraishi, Corrosion Science, 52, 933 (2010). 